ence, viz., the tying the splenic artery; in which case, doubtless, a sufficient quantity of splenic product is conveyed into the porta for the purposes of nutrition, or rather, perhaps, for the formation of bile.

If I am right in my views of the physio. logy of the spleen, as I believe I am, the operation of tying the splenic artery hids fair to become an operation of no ordinary or limited application; for Liebig has shown the omnipotent agency of these "carriers of oxygen" in the production of disease.

$I$ have now operated on fifty diseased rabbits, first losing two out of three, and latterly not one in three, perhaps from now tying only the splenic artery; perhaps from experience of the nature of the accidents of the operation; possibly from variation in the method and locality of the operation itself; and whenever I may be called to a patient moribund, in the face of the common remedies, from inanition arising from disease of the nutrient circulation, rather than from structural disorganisation, as in some cases of phthisis and marasmus, where death ensues not from the disease which meets the eye, but from the destroying cachexy, call it tuberculous or scrofulous, or what you will (for I am too old a student in philosophy to be satisfied with words unless those uords represent things and nature of things), which is the very nature or law of the disease, and is equally the cause of lung consumption in the human subject, of liver consumption in the rabbit, and of splenic consumption in a third. Whenever I may be so situated, pointing out to the patient and attendants the dangerless, but at the same time experimental, nature of the operation, I will throw into the jugular vein, in the manner directed by Dr. Blundell, a few ounces of blood, as I have often thrown drachms into the rabbits before operating, and at once proceed to take up the splenic artery; a work of two or three minutes at most. A faint hope is better than none at all-a chance of life than inevitable death. Circumstances being the same, do not the same effects follow the same causes? Why, then, letting alone the question of tubercular cicatrisation, there is strong hope that the tying the splenic artery will arrest tubercular disease in the human subject as it arrests it in the rabbit.

Kingsland-road, Sept. 28, 1842.

P. S.-I propose to enlarge upon this interesting subject at an early opportunity, and report other cases of the operation in different diseases, as well as in consumption, now in a state of probation. With reference to remarks of correspondents on my recent paper, I prefer answering them in the "lump" rather than entering into a peddling controversy, and will, therefore, wait a week or two, promising to occupy even then but very little of the valuable space of THE LANCET on the matter.

\section{A CASE OF DISEASED VISION.}

\section{By William KeIr, Lecturer on Science.}

I AM now in my 57 th year; my sight was originally near, but not distressingly so. At eighteen years of age $I$ could read at the distance of twelve inches. About that age I became acquainted with concave glasses, and was so delighted with the distant view and sharp outline they gave to objects that I began to wear them habitually, when reading and writing, as well as when walking. The consequence was I soon became much nearer-sighted, and had to increase the depth of my glasses. This from time to time I continued to do; and I was distressed to find that with every increase of power my vision finally settled, for reading, at twelve inches, or within it; whilst everything was as indistinct and ill-defined at a distance as before I began to wear glasses. The right eye I found to have not much more than half the focal distance of the left; in consequence, not only when the eyes are bare, but also when the glasses are on, objects appear double, the shadowy one being higher apparently than the real.

For many years I have been more or less annoyed with musce volitantes. These, I have been inclined to think, proceeded in many instances from the state of the stomach, or from nervous irritation. In high nervous irritation gleams of light and brilliant sparks, and sometimes coloured coruscations, have seemed to emanate from my eyeballs.

In March, 1841, I made a short sea-voyage, during which 1 was very little annoyed with sickness, but through irregularity in diet my stomach was somewhat disordered. After landing, for several nights, in the dusk and in the dark, I saw coloured coruscations and circular halos of light, as if surrounding the eye.

The days were exceedingly bright, and for many hours each day $I$ was engaged in reading or consulting a book which had a great deal of small print in it. This was done in a $u$ hite room, into which the sun shone brilliantly. In the evening, studies in the same book were prosecuted with a small candle: I know not whether it was owing to the severity of the application, the brilliancy of the light in which it was conducted in the morning, the transition to the comparative gloom of the evening, or the state of the digestive organs, but at the end of a fortnight I became conscious of some apparent disorganisation of the visual organs. 'The print would disappear and reappear. An undulating cloud seemed to be floating before my eyes, with occasional openings in it ; through the openings I could see the print distinctly, but it immediately became obscured, a denser part of the cloud intervening.

I desisted from my close study; but if that 
had been the cause of injury (to, I suppose, the retina), it was too late, for every object had the same clouded appearance. Faces seemed to have black, ill-defined, large blotches on them; bright objects, as fireirons, exhibited a tremulous, undulating light and shade; the large white letters painted on a black ground, on the ends of the streets, became ill-defined, and shaggy on the edges, as if fringed with hoar-frost. Besides the misty undulation, and dark scalylooking floating specks, a general dimness of vision had evidently been induced, for all $\mathrm{my}$ manuscripts and books appeared uncomfortably obscure and faint. As light passing through glass is necessarily partly lost, I Jaid aside the use of glasses, to which I had been constantly habituated for thirty-eight years, and $I$ had rather more light to read with.

My medical adviser's suspected a determination of blood to the head, or some congestion there. I was leeched on the temples, and blistered on the back of the neck; I also took blue pill and chalybeate drinks. These external and internal applications produced no sensible improvement of my vision, though I think they rather relieved a dull pain inward from the temples, to which $I$ am still subject, and which is thought to proceed from the optic nerve.

In the winter I was confined for many weeks to a darkened chamber, through in. flammation of the chest; but neither the seclusion from light, nor the low regimen and severe physickings to which, for my inflammation, I was subjected, produced any sensible improvement in my sight.

Recently I have not noticed the coruscations much, but often, when I shut my eyes, I observe a small bright light, which gradually fades away. I should have mentioned that the retina throughout has been unnaturally retentive of impressions caused by faint impulses of light. In a dark room, a bedchamber, for instance, on turning round from the window, faintly illuminated by a street lamp, I have been sensible to light about my eye, for, I should think, at least a whole second. D'Arcy limits the continuance of the impression of light on the retina to the eighth part of a second.

I sometimes see the appearance of welldefined black Roman capitals in the air, $\mathbf{T}$ or $\mathbf{X}$, for instance; and sometimes $I$ have a hasty evanescent glimpse of a whole word, as if printed in Greek small letters. I have not often the cobweb sensation, described as a precursor of amaurosis, but it occurs occasionally.

Some engagements into which I entered of late have made me use my glasses more than I had done in the twelve months preceding; and whether it be that the shortest-sighted eye (which is the right one) has come more into action, or that there is some more decided insensibility in parts of one or both retinæ, I have become sensible to phenomena nearly new to me. Lines of print oc. casionally appear curved, and actually undulating: so also do straight objects (especially if they be bright) when moved in a horizontal position. Perpendicular lines have a dent inward from the left hand, which runs, as I follow it with my eye, from the top to the bottom. Perpendicular printed letters, l, f, k, b, \&c., appear broken. backed, the dent being towards the right hand. Any small Roman letter in a word often assumes the appearance and position of an italic.

Rings, circles, and all circular or globular objects, often lose their symmetrical appearance. I do not remember that in any instance they assume an elliptical form, but they appear compressed and dimpled in every direction. The universal dimness remains almost uniformly permanent; for though a gleam, like that of sunshine, sometimes illuminates an object, it instantly fades away.

Thinking that the history of a disease of this nature (which few patients would be at the pains to record) may be useful to professional men and physiologists, I have written it at full length. My own impression is, that it is a case of incipient amaurosis ; for I have no idea that any of the phenomena arise from disease of any of the phrenological organs-form, size, weight, colour; they seem to proceed either from functional or structural derangement in the organ of vision itself, or that portion of the brain connected with it.

Belfast, 4, N. Thomas-street, June 22, 1842.

P.S.-Since this account was written I had an electric stroke sent through each eye, in the direction of the optic nerve, but without any sensible benefit: nor am $I$ at this date aware of any material alteration in the state of my vision, at least of any improvement.

Sept. 26, 1842.

\section{GIDDINESS, ATTENDED WITH FALLING,}

IN A CHILD AGED THREE YEARS. CUIRED.

To the Editor of THE LANCET.

SrR,-The following case, which I send under the above title, is so interesting, that I feel satisfied (though the treatment was bomoeopathic, and the remedies given were administered in the minute doses, used by homoeopathic practitioners) that you will deem it acceptable to the readers of your Journal. Yours, \&c.

London, Oct, 4, 1842.
JoHn EPPs. 